\title{
FOTOGRAFIA E FANTASMAGORIA EM DOM CASMURRO
}

\author{
Carolina Sá Carvalho \\ Princeton University \\ Princeton (NJ), Estados Unidos
}

\begin{abstract}
Resumo: O artigo investiga o papel do retrato fotográfico no romance Dom Casmurro, de Machado de Assis. Embora esteja presente em outras obras do escritor, como em Memorial de Aires ou Esaú e Jacó, apenas em Dom Casmurro a fotografia assume uma função determinante na estrutura da narrativa. A hipótese é a de que, nesta autobiografia ficcional de um personagem obcecado por reconstituir os laços entre o presente e o passado, as aparências e a realidade, o rosto e a alma, Machado põe em jogo questões comuns ao imaginário fotográfico do século XIX, quando os retratos adentram as casas burguesas. Dentre essas questões está o tema - propriamente moderno - da identidade, da divisão do sujeito e do desdobramento da personalidade, tema caro aos estudos de Machado, dentre os quais os de Antonio Candido, Augusto Meyer e, mais recentemente, José Luiz Passos.
\end{abstract}

Palavras-chave: fotografia; Dom Casmurro; identidade; retrato.

\section{Photography and imaginary in Dom Casmurro}

\begin{abstract}
This paper investigates the role of the photographic portrait in Dom Casmurro, by Machado de Assis. This fictional autobiography of a character obsessed by the reconstruction of the links between the present and the past, appearance and reality, face and soul deals with questions which are also part of the photographic imaginary of the $19^{\text {th }}$ century, when photographic portraits become part of every bourgeois home. Among these questions we find the theme of identity and of the duplication of the self, which are also present in Machadian studies such as those developed by Antonio Candido, Augusto Meyer and, more recently, José Luiz Passos. Even though photography appears in several of Machado de Assis's novels, such as Memorial de Aires or Esaú e Jacó, only in Dom Casmurro is it determinant for the structure of the narrative.
\end{abstract}

Keywords: photography; Dom Casmurro; identity; portrait. 
Multiplicando rostos, fazendo-os circular ou integrando-os em álbuns de família, os retratos fotográficos haviam ocupado, já na segunda metade do século XIX, uma posição privilegiada na vida e no imaginário urbano das mais diversas cidades do mundo. No Rio de Janeiro sua difusão contou com o entusiasmado incentivo do imperador Dom Pedro II, ${ }^{1}$ que, além de fotografar e apoiar a entrada de fotógrafos profissionais no país, distribuía sua própria imagem através de retratos fotográficos. Inseridos nos álbuns familiares cariocas, os retratos do imperador eram colecionados ao lado das imagens de parentes, de amigos, e até de personalidades nacionais e estrangeiras. Ser fotografado no século XIX significava, entre outras coisas, entrar para essa respeitável comunidade. ${ }^{2}$

Outra prática comum era pendurar na porta de casa o retrato de seu proprietário, ou presentear um amigo com um retrato pessoal. O retrato familiar burguês havia assumido, principalmente nas quatro últimas décadas do século, uma função mediadora não apenas entre presente e passado, como também entre o público e o privado, ou o interior e o exterior, tornando-se uma forma privilegiada de constituir simultaneamente a história individual e a imagem pública dos indivíduos. Minha hipótese é a de que é também dessa mediação, ou do desejo por estabelecê-la, que fala o romance Dom Casmurro. Não à toa, a fotografia assume uma função importante ao longo da narrativa: é emanação do passado e objeto de afeto; imagem que garante a representação social e prova da suposta infidelidade de Capitu, a esposa do narrador Bento Santiago.

O crítico brasilianista Thomas Sträter ${ }^{3}$ já havia apontado a relação entre o olhar

\footnotetext{
${ }^{1} \mathrm{O}$ imperador adquiriu seu próprio equipamento de daguerreotipia oito meses antes que ele começasse a ser comercializado no Brasil, em 1840. Ver: SCHWARCZ, Lilia Moritz. As barbas do imperador. São Paulo: Companhia das Letras, 1999. p. 502.

2 Sobre a fotografia oitocentista e a construção de uma "comunidade 'democrática' do visível", ver: LISSOVSKY, Mauricio. Guia prático das fotografias sem pressa. In: HEYNEMANN, Cláudia; RAINHO, Maria do Carmo (Orgs.). Retratos modernos. Rio de Janeiro: Editorial Arquivo Nacional, 2005. p. 7.

${ }^{3}$ STRÄTER, Thomas. De retratos, espelhos e reproduções: o olhar fotográfico de Machado de Assis. In: ANTUNES, Benedito Antunes; MOTTA, Sérgio Vicente Motta (Orgs.). Machado de Assis e a crítica internacional. São Paulo: Editora Unesp, 2009. p. 91-128.
} 
narrativo de Machado e a fotografia, através do que chamou de uma "percepção para a reprodutibilidade". O termo procura dar conta da atenção prestada por Machado às semelhanças e reproduções que desestabilizam a unidade do indivíduo e a relação entre o real e a representação. Mas à relação entre representação e realidade, e entre unidade e multiplicidade, creio somar-se a ênfase de Machado de Assis na existência temporal e moral dos sujeitos, aspectos também essenciais ao imaginário fotográfico oitocentista. Em Dom Casmurro, particularmente, é através de um olhar voltado para as imagens do passado que o narrador busca a verdade e a unidade entre o que foi e o que se tornou, assim como entre o que parece ser e o que é.

\section{Rosto ou fisionomia?}

O romance começa com algumas imagens: reproduções arquitetônicas, ídolos romanos e sombras do passado. O narrador conta-nos que habita uma casa construída nos mínimos detalhes à imagem da casa de sua infância. Mesma arquitetura, mobília, decoração e os mesmos medalhões de César, Augusto, Nero e Massinissa pintados nas paredes. O simulacro, no entanto, não é capaz de satisfazer-lhe o desejo de reconstituir o passado: "não consegui recompor nem o que foi nem o que fui. Em tudo, se o rosto é igual, a fisionomia é diferente". ${ }^{4}$ É da assimetria entre passado e presente, mas sobretudo entre o exterior e o interior, entre o visível e o invisível, que se trata. O rosto, como superfície, pode ser inventado, mascarado, reproduzido ou mimetizado com relativa facilidade. Já a fisionomia, como aquilo que remete a superfície visível aos movimentos invisíveis da alma, depende da crença de que a vida interior (a alma, o caráter, as emoções) é não apenas estável, como passível de ser apreendida através do olhar.

Embora tenha suas raízes na Antiguidade, relacionado à quiromancia e outras formas mágicas de adivinhação, é apenas a partir da modernidade clássica, ${ }^{5}$ sob a influência da divisão efetuada por Descartes entre alma e corpo, que o estudo da

\footnotetext{
${ }^{4}$ ASSIS, Machado de. Obra completa. v. 1. Rio de Janeiro: José Aguilar, 1962. p. 808. (Doravante referida apenas como OC.)

5 Utilizo aqui a terminologia de Foucault para falar do período que antecede a modernidade. Ver: FOUCAULT, Michel. As palavras e as coisas. São Paulo: Martins Fontes, 2002.
} 
fisionomia torna-se o conhecimento racional que pretende decifrar o mundo interior a partir dos signos corporais. ${ }^{6}$ A partir do século XIX, auxiliado pelas novas técnicas de visualidade, passa a desempenhar um papel importante nas recém-estabelecidas ciências do homem, em seu esforço por tornar o indivíduo um objeto de saber. Não à toa, o retrato fotográfico foi um recurso largamente utilizado na psiquiatria, na criminologia, na antropologia e nas ciências sociais como forma de aplicar a fisiognomonia ao estudo dos tipos sociais ou patológicos.

Mas independentemente do quão sistematizada se tornou, a fisiognomonia não deixou de ser a promessa de um conhecimento sobre o oculto, sobre aquilo que, no homem, teimava em não se dar ao olhar: o caráter, as paixões, as doenças da alma ou os desvios de personalidade. E é com tais questões, postas em jogo nas relações entre a constituição da imagem (especialmente a imagem do rosto) e o mundo de intenções, interesses e desejos ocultos, que se depara o narrador de Dom Casmurro ao tentar reconstituir o passado e encontrar o enigma que desvendaria seu presente. Trata-se, portanto, de um problema similar àquele enfrentado pelos estudos fisiognomônicos que buscam, a partir da aparência, o desvelamento da interioridade e, nesta, a causa dos atos dos indivíduos. Se toda a narrativa de Dom Casmurro é uma busca por desvendar as intenções que explicariam o triste fim de seu casamento, esta se dá através de um olhar atento para a aparência: a expressão franca do melhor amigo, os olhos da esposa ou os trejeitos do filho.

Mais do que apenas de intenções, portanto, é da atribuição de responsabilidade que se trata. Em um livro recente, José Luiz Passos sugeriu que a dissimilaridade, "o fenômeno de estar fora de si e examinar-se", ${ }^{7}$ está na raiz da concepção machadiana da pessoa humana. Tal desdobramento do "eu" está relacionado a uma consciência moral profundamente moderna, através da qual o sujeito olha para si e para o seu passado em busca das explicações para a vida presente. A análise de José Luiz Passos ajuda-nos a entender o narrador de Dom Casmurro como aquele que tenta unir as pontas entre os

\footnotetext{
${ }^{6}$ Para um resumo histórico da fisionomia e suas implicações na cultura visual, ver: GUNNING, Tom. In your face: physiognomy, photography, and the gnostic mission of early film". In: Modernism/Modernity 4.1 Baltimore: The Johns Hopkins University Press, 1997. p. 1-29.

${ }^{7}$ PASSOS, José Luiz. Machado de Assis: o romance com pessoas. São Paulo: Edusp; Nankin, 2007. p. 172.
} 
acontecimentos e as intenções, ou entre as ações e a consciência. No entanto, apesar de colocar em cena a busca ansiosa dos personagens por reconstituir os elos entre presente e passado, ou entre exterior e interior, o autor nunca chega a tornar claras, unas e estáveis as intenções de seus personagens. Machado termina por sugerir o inverso do que propunha o positivismo realista que permeou o desenvolvimento da fisionomia como ciência: rosto e alma nunca se encontram em uma relação estável de causa e efeito.

No conto "O espelho", temos um exemplo de como a formação da imagem, em Machado de Assis, torna complexa a fisionomia. O personagem Jacobina narra um episódio da sua vida para demonstrar a teoria de que todos os homens possuem duas almas, uma interior e uma exterior. Quando jovem, é nomeado alferes da Guarda Nacional e ganha de presente uma farda. O reconhecimento por parte de parentes e amigos é imediato e, na fazenda de sua tia, todos passam a chamá-lo "Senhor Alferes". Mas a tia precisa viajar com urgência e deixa a fazenda a seu cargo. Os escravos aproveitam para fugir e Jacobina vê-se subitamente desprovido do olhar do outro, que havia se tornado indispensável à instituição da farda de alferes e, simultaneamente, da sua própria identidade. A tal ponto esse olhar que vem de fora havia se tornado a "sua alma", que, ao olhar-se no espelho, a sua imagem aparece esfumada, difusa. É então que tem a ideia de vestir a farda e novamente postar-se em frente ao espelho. Apenas no reflexo que lhe devolve a imagem da figura fardada volta a encontrar-se inteiro.

O narrador, que inicia o conto postulando a teoria de que os homens possuem duas almas, parece concluir pela unicidade: só o que existe são as aparências. O olhar externo é o único que determina a identidade. O que ele não afirma, apenas nos deixa entrever, é que resta ao personagem, entretanto, a consciência do abismo de seu próprio vazio interior. Ao revirar o olho, voltando-o para esse vazio, ele preserva sua existência, mesmo como negação. Há, portanto, ao contrário do que nos quer fazer crer Jacobina, profundidade no personagem machadiano, mesmo que, como nos lembra Augusto Meyer $^{8}$ ao aproximar Machado de Dostoiévski, esse olhar que se volta para a interioridade seja profundamente niilista, esvaziado de qualquer potencial redentor.

\footnotetext{
${ }^{8}$ MEYER, Augusto. O homem subterrâneo. In: Machado de Assis 1935-1958. Rio de Janeiro: José Olympio, 2008.
} 
O olhar que perscruta, portanto, jamais será apenas aquele olhar positivo que desvenda, nos sinais do rosto, a expressão dos segredos da alma. $\mathrm{O}$ desdobramento do indivíduo, ou, como sugeriu José Luiz Passos, a sua "dissimilaridade", está relacionado não apenas à fissura entre aquele que olha (conhece) e aquele que é olhado (objeto de conhecimento), própria do sujeito autorreflexivo moderno, mas também à identidade que os personagens constroem para si, ou às imagens de si que manipulam deliberadamente para o olhar do outro. A perspicácia do conto está em complicar a dinâmica entre olhar, rosto e alma: não apenas relativiza o caráter unívoco da personalidade, como fala também do próprio processo de constituição da imagem. ${ }^{9}$

Em Dom Casmurro, o exercício de olhar para o passado, em que a visão tenta construir uma figura de si e dos outros, acaba por relacionar estas questões ao problema da fisionomia. O rosto se torna meio de simulação e dissimulação, e a imagem do rosto, o retrato fotográfico, converte-se em objeto fantasmático, no qual se adivinham segredos e se projetam desejos.

\section{Fotografia: fantasmas e imaginação}

A primeira imagem que aparece cindida no romance é a imagem que o narrador tem de si: "Um homem consola-se mais ou menos das pessoas que perde; mas falto eu mesmo, e esta lacuna é tudo", ${ }^{10}$ diz Dom Casmurro sobre a tentativa fracassada de reconstituir o passado na casa de Matacavalos. É então que os bustos dos imperadores

\footnotetext{
${ }^{9}$ Seria interessante comparar a dinâmica descrita por Machado de Assis no conto "O espelho" com aquela que se dava nos estúdios fotográficos da época, da qual sabemos que o próprio autor participou. Em uma análise da técnica do retrato burguês inventada por Disdéri em 1855 - a carte de visite -, Mauricio Lissovsky conta que uma das recomendações do mestre francês aos fotógrafos era a de que estes conhecessem bem o tipo e o caráter do modelo a ser retratado. O interessante está no método que constrói para constituir a carte de visite como uma imagem pública do indivíduo: em primeiro lugar, o fotógrafo deve isolar, em meio à balbúrdia de movimentos involuntários "a 'melhor' expressão facial de cada indivíduo [...] Afinal, uma configuração da fisionomia é escolhida. Chega-se à etapa mais difícil do ato fotográfico. Como reviver essa expressão no rosto do modelo? [...] Baseado na 'faculdade inata de imitação' dos seres humanos e no fato de que atitudes e expressões são socialmente contagiosas, o fotógrafo assume, ele próprio, a expressão escolhida, 'identificando-se' com a 'situação moral' desde onde ela emergiu. Induzida pela expressão do fotógrafo, a face do modelo assume então a configuração desejada e o retrato pode ser feito. [...] Neste curioso jogo de espelhos, o modelo, mirando-se no fotógrafo, torna-se espectador de si mesmo." LISSOVSKY, Mauricio. Guia prático das fotografias sem pressa. In: HEYNEMANN, Cláudia; RAINHO, Maria do Carmo (Orgs.). Retratos modernos. Rio de Janeiro: Editorial Arquivo Nacional, 2005. p. 11.
}

${ }^{10}$ OC, p. 808. 
romanos pintados na parede dão-lhe a ideia de narrar sua história. Novo fracasso, pois o "eu" que unificaria a experiência da memória permanece ausente, fragmentado na experiência moderna do tempo. Dom Casmurro não é capaz de reconhecer-se em Bentinho, seu "eu" passado, nem em seu filho, legado futuro, figura da possibilidade de continuidade do indivíduo na história.

Se não encontra a unidade tranquilizadora na história, tampouco logra reconciliar-se com ela: "Deste modo, viverei o que vivi", ${ }^{11}$ diz o narrador, incapaz de aceitar a inexorabilidade do tempo. Reviver o passado, reencontrar os fantasmas, constitui-se, no tecer da narrativa, em uma tentativa de dar sentido ao presente. Será que o futuro já estava inscrito ali? Onde? Nos olhos oblíquos de Capitu? O narrador busca minuciosamente as evidências da traição de sua esposa em atitudes, expressões e acontecimentos.

Assim, do mesmo modo como é impossível reencontrar-se no tempo como um sujeito único e igual a si mesmo, portador não apenas de um rosto, como de uma personalidade, também o é encontrar aí a verdade ou o sentido dos acontecimentos. Como sugeriu Katia Muricy, ${ }^{12}$ escrever não instaura, para o memorialista de Machado, nem a unidade subjetiva da experiência, nem a sua verdade. Resta, no entanto, uma constelação de imagens, superfícies e semelhanças. Índices que, mais do que serem portadores de uma verdade definitiva que nós leitores devemos apreender, multiplicam sombras, fantasmas, desejos e outros seres invisíveis.

Não à toa, o romance é rico em alusões a retratos fotográficos, os duplos dos rostos, desdobramentos do indivíduo que encantaram o imaginário oitocentista. Entre todos os gêneros praticados e funções cumpridas pela fotografia na segunda metade do século XIX, o retrato foi certamente o mais difundido. Machado de Assis não apenas se deixou fotografar diversas vezes, ${ }^{13}$ como escreveu uma crônica, em 1864, sobre uma de suas visitas ao célebre retratista Joaquim Insley Pacheco, onde se reuniam "no mesmo

\footnotetext{
${ }^{11}$ Ibidem.

${ }^{12}$ MURICY, Katia. A razão cética: Machado de Assis e as questões de seu tempo. São Paulo: Companhia das Letras, 1988.

${ }^{13}$ É possível ver os retratos de Machado de Assis e sua esposa em: GUIMARÃES, Hélio de Seixas; SACCHETTA, Vladimir. A olhos vistos: uma iconografia de Machado de Assis. São Paulo: Instituto Moreira Salles, 2008.
} 
salão ou no mesmo álbum, os rostos mais belos do Rio de Janeiro". ${ }^{14}$ Sem dúvida, o "milagroso aparelho" e, principalmente, os rostos que reproduzia não passaram despercebidos ao escritor. Minha hipótese é a de que é no âmbito da milagrosa duplicação do rosto, do desdobramento do sujeito e da imaginação que o retrato fotográfico aparece em Dom Casmurro.

Embora a fotografia, como técnica de reproduzir mecanicamente o real, tenha servido como importante instrumento para um novo positivismo da visão, ela foi também experimentada, principalmente no século XIX, como um fenômeno misterioso, que parecia diluir as identidades, reproduzindo infinitamente as pessoas e os objetos, criando um mundo de duplos fantasmáticos. Trata-se, aqui, da percepção de um caráter icônico da imagem, para utilizar a expressão de Charles Peirce, ${ }^{15}$ e o assombro das primeiras décadas com a sua capacidade de gerar duplos perfeitos. Como sugeriu Tom Gunning: a "fotografia como reprodução mecânica pode minar as identidades através do seu potencial icônico para criar duplos de uma similaridade inalterável". ${ }^{16}$

À possibilidade de reproduzir seu referente, desdobrando-o, soma-se o fato de que o processo indicial ${ }^{17}$ de fabricação de imagens serviu não apenas para que ela fosse apreendida como evidência de um real visível, mas também, paradoxalmente, para contestar a suposta estabilidade da ideia de evidência documental. Por um lado, a relação de contiguidade entre a imagem e o referente certamente desempenhou um papel importante nos discursos de verdade sobre a fotografia: ela seria capaz, como nenhuma outra técnica de representação, de eliminar tanto a mediação da linguagem quanto as contingências e especificidades da visão. A invenção da primeira imagem técnica do Ocidente - The pencil of nature $-{ }^{18}$ parecia significar que finalmente a subjetividade

\footnotetext{
${ }^{14}$ Machado de Assis, Diário do Rio de Janeiro, 07.08.1864. Citado em: STR ÄTER, Thomas. De retratos, espelhos e reproduções: o olhar fotográfico de Machado de Assis, cit., p. 109.

${ }^{15}$ PEIRCE, Charles. Selected writings. New York: Dover, 1958.

16 Tradução minha. No original: "photography as mechanical reproduction may undermine indentity through its iconic power to create doubles of an unaltering similarity". GUNNING, Tom. O retrato do corpo humano: a fotografia, os detetives e os primórdios do cinema. In: CHARNEY, Leo; SCHWARTZ, Vanessa. O cinema e a invenção da vida moderna. São Paulo: Cosac \& Naify, 2004. p. 67.

${ }^{17}$ Refiro-me aqui à teoria dos signos de Peirce: "I define an Index as a sign determined by its Dynamic object by virtue of being in a real relation to it". PEIRCE, Charles. Selected writings, cit., p. 391.

${ }^{18}$ Título dado por Fox Talbot ao primeiro livro ilustrado com fotografias.
} 
humana poderia ser superada pela objetividade das máquinas. ${ }^{19}$ Indicialidade, nesse contexto, significava fixar a realidade.

Por outro lado, a compreensão da fotografia como índice pôde também apontar para uma inevitável aleatoriedade da imagem. Como impressão direta da luz na superfície sensibilizada, há algo na fotografia que irá sempre exceder aquilo que o fotógrafo vê à sua frente ou deseja mostrar. Nas palavras do antropólogo das imagens Christopher Pinney, "Se pensarmos na imaginação e no pincel do pintor compondo um filtro dotado da capacidade de exclusão, a lente da câmera, por sua vez, jamais pode ser fechada, pois nela sempre entrará algo alheio à intenção do fotógrafo". ${ }^{20}$ Aqui, a indicialidade da imagem fotográfica deixa de ser garantia de estabilidade do representado e torna-se a abertura para o que Pinney chamou de "múltiplas superfícies". Daí certa volatilidade da imagem fotográfica, sua tendência a ser ressignificada, reapropriada e circulada.

Estas duas características da fotografia, que dependem da possibilidade de a imagem destacar-se de seu referente, frisam aspectos da sua recepção cultural que ultrapassam o uso histórico-científico. Insistem na ideia de que a fotografia foi objeto aberto a múltiplas apropriações e, sobretudo, à imaginação. Deste modo, colocam-na no centro de uma experiência da modernidade que toca em dois temas caros a Machado de Assis: o desdobramento da identidade e a dúvida entre o que é real e o que é imaginado.

\section{Os retratos em Dom Casmurro}

Bento mostra uma peculiar fascinação pelos retratos. Face à expressão da felicidade conjugal eternizada nas imagens de sua mãe e seu pai, ele se pergunta sobre

\footnotetext{
${ }^{19}$ Sigo aqui o argumento de: CRARY, Jonathan. Techniques of the observer. Cambridge (Massachussets): MIT Press, 1990. O autor relaciona a "crise da representação" e, mais especificamente, o momento em que a visão perde a sua transparência e objetividade e ganha corpo e temporalidade, à emergência de diversas pesquisas empíricas que buscavam desenvolver uma técnica capaz de dominar o real, de prescindir do aparato cognitivo humano. Pesquisas estas relacionadas ao próprio surgimento da fotografia.

${ }^{20}$ Tradução minha. No original: "If we think of the painter's imagination and brush as a filter capable of complete exclusion, then the lens of the camera can never be closed because something extraneous will always enter into it". PINNEY, Christopher. Introduction: "How the other half...". In: PETERSON, Nicolas (Eds.). Photography's other histories. Durham; London: Duke University Press. 2003. p. 6.
} 
as implicações temporais da fotografia: "Se padeceram moléstias, não sei, como não sei se tiveram desgostos [...] Depois da morte dele, lembra-me que ela chorou muito; mas aqui estão os retratos de ambos, sem que o encardido do tempo lhes tirasse a primeira expressão. São como fotografias instantâneas da felicidade." ${ }^{21}$ Para o narrador, que conta a derrocada de seu próprio casamento - um casamento que, aos olhos de todos, prometia ser muito feliz -, o fascínio pela imagem parece vir, em primeiro lugar, de sua capacidade de trazer-nos um fragmento do passado. Mais uma vez, a análise feita por José Luiz Passos da constituição da pessoa moral em Machado nos dá uma pista sobre a relação de Dom Casmurro com o tempo, pois se "pessoas são seres que perduram no tempo", ${ }^{22}$ resgatar o passado é ter consciência do que fomos e, simultaneamente, do que poderíamos ter sido. O que o narrador busca é o modo como tal promessa de felicidade pôde ser desvirtuada, é a explicação e a responsabilidade pelo seu presente infeliz.

A imagem "instantânea" ultrapassa, portanto, o papel de representação de um dado momento histórico. Como fragmento que salta da história ou da biografia dos pais de Bento, a imagem preserva sua própria expressão e seu(s) próprio(s) futuro(s). Bento chega a questionar se de fato os pais foram felizes como mostra o retrato. Mas acaba por não levar o questionamento adiante: a imagem está ali, sobreviveu ao seu próprio referente, e ali (talvez apenas ali) está preservado o passado feliz e seu futuro possível. Será que na imagem do passado de Bento e Capitu já estava contido o seu desenlace?

Ao gerar duplos que sobrevivem à morte de seus referentes, as imagens também podem gerar angústia, como a fotografia de Escobar a assombrar a imaginação ciumenta do personagem: "Pois até os defuntos! Nem os mortos escapam aos seus ciúmes!", ${ }^{23}$ protesta Capitu. A fotografia, portanto, não é apenas imagem, mas objeto no qual se depositam desejos, raivas e afeições.

Pendurada na parede, a fotografia de Escobar possui a dedicatória do amigo. Ela é também relíquia, forma de possuir, mais do que uma imagem, um traço, uma impressão física do outro. ${ }^{24}$ Para demonstrar que Capitu logrou conquistar o coração de

\footnotetext{
${ }^{21}$ OC, p. 815.

${ }^{22}$ PASSOS, José Luiz. Machado de Assis: o romance com pessoas, cit., p. 177.

${ }^{23}$ OC, p. 936

${ }^{24}$ Diversos autores - entre os quais podemos citar Roland Barthes (1984) e Phillipe Dubois (2006) -
} 
sua mãe, Bento lembra que a menina ganhou um retrato em miniatura desta. Capitu beijou o retrato, ao que D. Glória correspondeu beijando a menina. A fotografia aqui é objeto de afeto, coisa a ser trocada, tocada, manipulada.

Nascido no ano do anúncio da invenção da fotografia por Daguerre, Machado de Assis presenciou, já adulto, o auge da propagação da prática de colecionar e presentear fotografias, impulsionada pela difusão do formato da carte de visite no Brasil, na década de 1860. O formato, patenteado por André Disdéri em 1855, havia barateado significativamente o custo do retrato, tornando-se a forma favorita de personalizar os cidadãos burgueses, de valorizar-lhes a figura e a posição social. Além do custo relativamente baixo, a carte de visite permitia a produção de uma série de imagens em um mesmo cartão, o que incentivava a distribuição de cópias entre parentes e conhecidos. A popularização deste dispositivo, dos seus procedimentos técnicos e estéticos, acabou por criar um padrão rigorosamente homogêneo, tornando-se quase indistinguíveis imagens feitas no Rio de Janeiro, em Nova Iorque ou em Paris, assim como no estúdio de um ou de outro fotógrafo. ${ }^{25}$

Arguto observador do teatro social, consciente da centralidade da imagem na vida burguesa (lembremos do conto "O espelho"), Machado não deixa de fazer referência ao fenômeno da carte de visite. Ao mencionar a fotografia de seu amigo Escobar, Dom Casmurro descreve com perfeição o modo como eram compostos esses retratos burgueses:

Uma só vez olhei para o retrato de Escobar. Era uma bela fotografia tirada um ano antes. Estava de pé, sobrecasaca abotoada, a mão esquerda no dorso de uma cadeira, a direita metida ao peito, o olhar ao longe para a esquerda do espectador. Tinha garbo e naturalidade. A moldura que lhe mandei pôr não encobria a dedicatória, escrita embaixo, não nas costas do cartão: "Ao meu querido Bentinho o seu querido Escobar 20-4-70". ${ }^{26}$

sublinham essa veneração que temos por certas fotografias; essa força, própria da imagem fotográfica, que opera como o desejo. Em geral, remonta-se esse investimento afetivo à relação indiciária do signo fotográfico com o seu referente: "Como impressão luminosa, a foto é presença íntima de algo de uma pessoa, de um lugar, de um objeto." (Henri van Lier, citado por: DUBOIS, Philippe. O ato fotográfico. Campinas: Papirus, 2006.).

${ }^{25}$ Ver: LISSOVSKY, Mauricio. Guia prático das fotografias sem pressa, cit., p. 3.

${ }^{26}$ OC, p. 923-924. 
A fotografia aqui é a construção da imagem própria para o olhar do outro. Em livro sobre as fotografias oitocentistas no Brasil, Mauricio Lissovsky sugere que as cartes de visite eram retratos morais, destinados a revelar o caráter distinto do retratado. A palavra "distinção" é utilizada em seu duplo significado, de dignidade e de diferença: "Por um lado, a distinção que assinala o caráter elegante, discreto e honrado de cada um dos membros da comunidade de fotografáveis; e, por outro, a distinção que dá a ver, em cada um, seu traço característico, sua peculiaridade, sua personalidade." ${ }^{27}$ A descrição que o narrador de Dom Casmurro faz da fotografia de Escobar revela o complexo equilíbrio que deveria ser estabelecido entre a pose convencional, que torna visível a semelhança moral entre os retratados, e a construção de uma imagem do caráter individual: "O retrato de Escobar pareceu falar-me; vi-lhe a atitude franca e simples, sacudi a cabeça e fui deitar-me." 28

Nesta breve digressão através das menções à fotografia em Dom Casmurro, pode-se perceber que ela vai se constituindo como um objeto de atenção do narrador. Um narrador, como já sugerimos, preocupado com a reconstituição do passado e com tentativa de ler, nas imagens, o seu significado. Assim chegamos ao momento em que a fotografia se torna de fato determinante na narrativa. Trata-se do capítulo número CXXXIX (será mero acaso este número aludir, em suas casas finais, ao ano do anúncio da invenção do daguerreótipo?), ${ }^{29}$ intitulado "Fotografia". Nesse momento, Bento vê no retrato de Escobar e em seu filho Ezequiel uma tal semelhança que esta se torna evidência da traição de Capitu. Abaixo reproduzo o pequeno capítulo na íntegra.

Palavra que estive a pique de crer que era vítima de uma grande ilusão, uma fantasmagoria de alucinado; mas a entrada repentina de Ezequiel, gritando: - "Mamãe! Mamãe! É hora da missa!" restituiume à consciência da realidade. Capitu e eu, involuntariamente, olhamos para a fotografia de Escobar, e depois, um para o outro. Este era aquele; havia por força alguma fotografia de Escobar pequeno que

\footnotetext{
${ }^{27}$ LISSOVSKY, Mauricio. Guia prático das fotografias sem pressa, cit., p. 8

${ }^{28}$ OC, p. 923.

${ }^{29}$ Devo a observação ao artigo "De retratos, espelhos e reproduções: o olhar fotográfico de Machado de Assis", de Thomas Sträter.
} 
seria o nosso pequeno Ezequiel. De boca, porém, não confessou nada; repetiu as últimas palavras, puxou do filho e saíram para a missa. ${ }^{30}$

A evidência de uma identidade que estava oculta - "este era aquele" - se revela no âmbito da imagem. Rapidamente o narrador pula da semelhança à igualdade, concluindo que certamente haveria fotos dos dois pequenos que seriam idênticas. A reprodução da imagem e a reprodução genética se sobrepõem. A consequência disto para a trama é que o filho, a partir de então, não pode ser visto por Bento senão como o duplo de Escobar, sua fotografia. A última imagem que aparece no romance, portanto, é o próprio Ezequiel, o duplo que sobreviveu ao seu referente:

Trajava à moderna, naturalmente, e as maneiras eram diferentes, mas o aspecto geral reproduzia a pessoa morta. Era o próprio, o exato, o verdadeiro Escobar. Era o meu comborço; era o filho de seu pai. [...] Eu, posto que a ideia da paternidade do outro me estivesse já familiar, não gostava da ressurreição. Às vezes, fechava os olhos para não ver gestos nem nada, mas o diabrete falava e ria, e o defunto falava e ria por ele. ${ }^{31}$

\section{Fotografia do invisível}

Para quem busca a unidade entre passado e presente, atrás de pistas e provas de um adultério, o uso que o narrador de Machado faz da fotografia é surpreendentemente ambíguo. Talvez possamos associá-lo ao que Roberto Schwarz ${ }^{32}$ apontou como aquelas "armadilhas" características dos narradores de Machado, que consistem em inicialmente nos seduzir a aderir ao ponto de vista que deveria ser criticado. A armadilha a que agora me refiro consiste em confundir ilusão e realidade, ou melhor, em borrar as fronteiras entre ambas justamente quando o narrador parece fixá-las. Quando Bento começa a duvidar de seu próprio julgamento - talvez prevendo que o leitor esteja fazendo o mesmo e, assim, antecipando-se a ele -, no momento em que considera a possibilidade de que aquilo que vê seja ilusório, fruto de sua própria loucura, é a fotografia que o

\footnotetext{
${ }^{30}$ OC, p. 936.

${ }^{31}$ OC, p. 940.

32 SCHWARZ, Roberto. A poesia envenenada de Dom Casmurro. In: PIZARRO, Ana (Org.). América Latina: palavra, literatura e cultura. v.2. São Paulo: Memorial, 1994.
} 
devolve à suposta realidade - a realidade do adultério. Até aí, muito bem, dado que a fotografia era entendida como cópia fiel do real. Mas sentimos que há um salto demasiado rápido, uma identificação dada como óbvia, entre fotografia e evidência.

A sugestão de Silviano Santiago de que o narrador em Dom Casmurro se constitui como um advogado que constrói uma retórica persuasiva pode nos ajudar a entender o argumento. Segundo Santiago, essa persuasão é construída sobretudo (e é aí que nos permite apreender sua falácia) por proximidade e verossimilhança, pela "entrega ao leitor daquilo mesmo que sua mente já está preparada para receber", ${ }^{33}$ ou seja, o senso comum.

Ao mencionar a fotografia logo após dizer que voltou à realidade, é provável que o narrador esteja contando com um determinado senso comum que relaciona a fotografia à evidência de um crime. Além de ser integrada na criminologia do século XIX para facilitar os processos de identificação e imputação de culpa, sendo inclusive utilizada em murais públicos, como as "galerias de criminosos e procurados", a fotografia também apareceu em inúmeras ficções policiais do período. Além disso, Tom Gunning $^{34}$ nota que um dos usos ficcionais mais comuns da "fotografia como evidência da ação do criminoso" lidava com o comportamento sexual, mais do que com o comportamento violento. No conto "Um escândalo na Boêmia", de Arthur Conan Doyle, por exemplo, Sherlock Holmes é contratado pelo grão-duque de Cassel Felstein para tentar evitar que um antigo caso amoroso com uma cantora de ópera venha à tona, atrapalhando seu noivado com uma princesa escandinava:

\footnotetext{
"Não consigo compreender Sua Majestade. Se esta jovem pessoa quisesse usar suas cartas para chantagem ou outros propósitos, como iria provar a sua autenticidade?"

"Pela letra"

"Ts, ts! Falsificada."

"Meu bloco de cartas particular."

"Roubado"

"Meu selo"

"Imitado"
}

\footnotetext{
${ }^{33}$ SANTIAGO, Silviano. Uma literatura nos trópicos. Rio de Janeiro: Rocco, 2000. p. 37.

${ }^{34}$ GUNNING, Tom. O retrato do corpo humano: a fotografia, os detetives e os primórdios do cinema, cit., p. 55.
} 


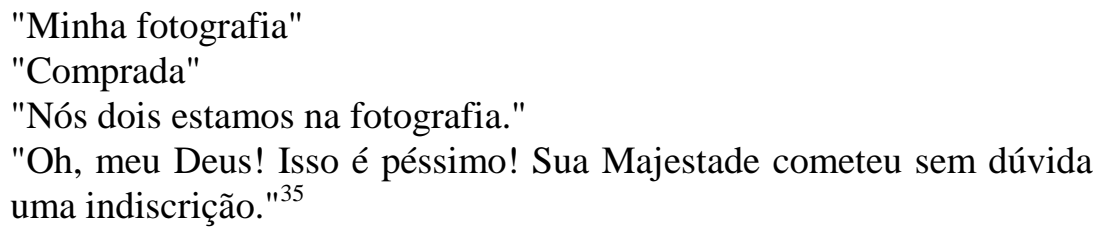

Para o detetive de Doyle, apenas a fotografia consiste em indiscrição, pois apenas ela é evidência incontestável daquilo que de outro modo poderia permanecer oculto. É provável que Machado também considere tal imaginário fotográfico quando escreve seu capítulo "Fotografia". No entanto, ao fazer de seu narrador, como sugeriu Santiago, um advogado (e não um detetive), Machado de Assis abre a possibilidade de duvidarmos dos pressupostos em que se baseia a sua própria lógica argumentativa.

Mas se não é "evidência incontestável", qual seria, alternativamente, a relação entre a fotografia e culpa? Quando Ezequiel adentra a sala, no capítulo CXXXIX, Bento o vê, olha para o retrato de Escobar e depois para Capitu. É na constelação de rostos que adivinha, como um astrólogo, o significado oculto nas semelhanças: o rosto do filho que entra, o rosto de Escobar na fotografia e o rosto de Capitu que trai o segredo. A fotografia serve, neste esquema astrológico, para fixar a culpa a partir da fixação e duplicação do rosto do amigo (já morto). Ou serviria ela para multiplicar os fantasmas de Bento?

Walter Benjamin chama atenção para as afinidades da fotografia com a psicanálise: "a natureza que fala à câmera não é a mesma que fala ao olhar; é outra, especialmente porque substitui a um espaço trabalhado conscientemente pelo homem, um espaço que ele percorre inconscientemente." 36 O termo "inconsciente ótico" é cunhado pelo autor para falar da relação que fotografia e psicanálise estabelecem entre o visível e o invisível (o consciente e o inconsciente) e da passagem de um a outro. De fato, a história da fotografia oitocentista foi marcada por esse desejo de trazer o invisível ao olhar: os retratos espirituais, a decomposição do movimento em Muybridge e Marey, as iconografias da insânia e das doenças da alma (como as do fotógrafo inglês Hugh

\footnotetext{
${ }^{35}$ Citado em: GUNNING, Tom. O retrato do corpo humano: a fotografia, os detetives e os primórdios do cinema, cit., p. 37.

36 BENJAMIN, Walter. Pequena história da fotografia. In: Magia e técnica, arte e política: ensaios sobre literatura e história da cultura. São Paulo: Brasiliense, 1994. p. 94.
} 
Diamond e dos assistentes do Dr. Charcot) são alguns exemplos.

[...] a fotografia revela nesse material os aspectos fisionômicos, mundos de imagens habitando as coisas mais minúsculas, suficientemente ocultas e significativas para encontrarem um refúgio nos sonhos diurnos, e que agora, tornando-se grandes e formuláveis, mostram que a diferença entre a técnica e a magia é uma variável totalmente histórica. ${ }^{37}$

Ao invés de um realismo fotográfico, talvez Machado Assis se interessasse pela fotografia justamente por esse seu caráter espectral, porque, mais do que representar $o$ mundo visível, é capaz de tornar mundos visíveis. A expressão "fotografia do invisível", que utilizamos para nomear esta seção, não vem de Benjamin, mas do romance Esaú e Jacó. $^{38}$ A frase aparece no capítulo XLI, na qual o conselheiro Aires vê um burro empacado levando pancadas de um carroceiro. A situação dura uns cinco ou seis minutos, até o burro cansar de apanhar e decidir se mover. O conselheiro Aires lê então nos olhos do animal um monólogo:

"Anda, patrão, atulha a carroça de carga para ganhar o capim de que me alimentas. Vive de pé no chão para comprar as minhas ferraduras. Nem por isso me impedirás que te chame um nome feio, mas eu não te chamo nada; ficas sendo sempre o meu querido patrão. Enquanto te esfalfas em ganhar a vida, eu vou pensando que o teu domínio não vale muito, uma vez que me não tiras a liberdade de teimar..."

"Vê-se, quase que se lhe ouve a reflexão", notou Aires consigo.

Depois riu de si para si, e foi andando. Inventara tanta cousa no serviço diplomático, que talvez inventasse o monólogo do burro. Assim foi; não lhe leu nada nos olhos, a não ser a ironia e a paciência, mas não se pôde ter que lhes não desse uma forma de palavra, com as suas regras de sintaxe. A própria ironia estaria acaso na retina dele. $\mathrm{O}$ olho do homem serve de fotografia ao invisível, como o ouvido serve de eco ao silêncio. Tudo é que o dono tenha um lampejo de imaginação para ajudar a memória a esquecer Caracas e Cármen, os seus beijos e experiência política. ${ }^{39}$

Vê-se como Machado nega aos pares representação e realidade, passado e

\footnotetext{
${ }^{37}$ Idem, p. 94-95.

${ }^{38}$ Mais uma vez, quem chamou a atenção para tal citação foi Thomas Sträter, no artigo citado.

${ }^{39}$ OC, p. 996
} 
presente, superfície e profundidade uma relação de causa e efeito. Assim como em "O espelho", o que resta ao narrador de Dom Casmurro, em meio à duplicação infinita dos rostos e ao jogo de olhares, é essa consciência profunda da impossibilidade do sujeito de fixar sua própria verdade. Se um astrônomo-fotógrafo um dia proclamou que "a placa fotográfica é a verdadeira retina do cientista.", ${ }^{40}$ Machado, por sua vez, disse que a retina do homem é uma placa fotográfica, capaz de tornar visíveis os seus fantasmas.

Referências:

ASSIS, Machado de. Obra completa. Rio de Janeiro: José Aguilar, 1962. v. 1.

BENJAMIN, Walter. Pequena história da fotografia. In: . Magia e técnica, arte e política: ensaios sobre literatura e história da cultura. São Paulo: Brasiliense, 1994.

CRARY, Jonathan. Techniques of the observer. Cambridge (Massachussets): MIT Press, 1990.

FOUCAULT, Michel. As palavras e as coisas. São Paulo: Martins Fontes, 2002.

GUIMARÃES, Hélio de Seixas; SACCHETTA, Vladimir. A olhos vistos: uma iconografia de Machado de Assis. São Paulo: Instituto Moreira Salles, 2008.

GUNNING, Tom. In your face: physiognomy, photography, and the gnostic mission of early film". In: Modernism/Modernity 4.1 Baltimore: The Johns Hopkins University Press, 1997. p. 1-29.

O retrato do corpo humano: a fotografia, os detetives e os primórdios do cinema. In: CHARNEY, Leo; SCHWARTZ, Vanessa. O cinema e a invenção da vida moderna. São Paulo: Cosac \& Naify, 2004.

HEYNEMANN, Cláudia; RAINHO, Maria do Carmo (Orgs.). Retratos modernos. Rio de Janeiro: Editorial Arquivo Nacional, 2005.

LISSOVSKY, Mauricio. Guia prático das fotografias sem pressa. In: HEYNEMANN, Cláudia; RAINHO, Maria do Carmo (Orgs.). Retratos modernos. Rio de Janeiro: Editorial Arquivo Nacional, 2005.

MEYER, Augusto. O homem subterrâneo. In: Machado de Assis 1935-1958. Rio de Janeiro: José Olympio, 2008.

MURICY, Katia. A razão cética: Machado de Assis e as questões de seu tempo. São Paulo: Companhia das Letras, 1988.

PASSOS, José Luiz. Machado de Assis: o romance com pessoas. São Paulo: Edusp; Nankin, 2007.

\footnotetext{
${ }^{40}$ LISSOVSKY, Mauricio. Guia prático das fotografias sem pressa, cit., p. 2.
} 
PEIRCE, Charles. Selected writings. New York: Dover, 1958.

PINNEY, Christopher. Introduction: "How the other half...". In: PETERSON, Nicolas (Eds.). Photography's other histories. Durham; London: Duke University Press. 2003.

SANTIAGO, Silviano. Uma literatura nos trópicos. Rio de Janeiro: Rocco, 2000.

SCHWARCZ, Lilia Moritz. As barbas do imperador. São Paulo: Companhia das Letras, 1999.

SCHWARZ, Roberto. A poesia envenenada de Dom Casmurro. In: PIZARRO, Ana (Org.). América Latina: palavra, literatura e cultura. São Paulo: Memorial, 1994. v. 2.

STRÄTER, Thomas. De retratos, espelhos e reproduções: o olhar fotográfico de Machado de Assis. In: ANTUNES, Benedito; MOTTA, Sérgio Vicente (Orgs.).

Machado de Assis e a crítica internacional. São Paulo: Editora Unesp, 2009. p. 91-128.

Carolina Sá Carvalho é doutoranda em Spanish and Portuguese Languages and Cultures na Princeton University e mestre em Comunicação e Cultura pela Universidade Federal do Rio de Janeiro. Publicou artigos em diversas revistas, como Galáxia (PUCSP) e FAMECOS, e capítulo no livro Imagens da cidade: espaços urbanos na comunicação e cultura contemporâneos, organizado por Angela Prysthon. E-mail: <cscarval@princeton.edu>

Recebido: 10/09/2011

Aprovado: 23/11/2011 